\title{
Regional Agricultural Drought Risk Assessment Method Based on Risk Transforming Process
}

\author{
Yanqi WEI \\ Hefei University of Technology \\ Yi CUI ( $\nabla$ ycui@hfut.edu.cn ) \\ Hefei University of Technology \\ Juliang JIN \\ Hefei University of Technology \\ Hiroshi ISHIDAIRA \\ University of Yamanashi: Yamanashi Daigaku \\ Haichao LI \\ University of Yamanashi: Yamanashi Daigaku \\ Shangming JIANG \\ Hefei University of Technology \\ Rongxing Z $\mathrm{HO}$ \\ Hefei University of Technology \\ Liangguang ZHOU \\ Hefei University of Technology
}

\section{Research Article}

Keywords: Drought hazard, Risk curves, Risk maps, Crop growth simulation, Huaibei Plain of Anhui Province

Posted Date: November 19th, 2021

DOl: https://doi.org/10.21203/rs.3.rs-1085277/v1

License: (c) (i) This work is licensed under a Creative Commons Attribution 4.0 International License.

Read Full License 


\title{
Regional Agricultural Drought Risk Assessment Method Based on Risk Transforming Process
}

\author{
Yanqi WEI ${ }^{1,2,3}$, Juliang JIN ${ }^{1,2}$, Yi CUI ${ }^{1,2^{*}}$, Hiroshi ISHIDAIRA ${ }^{3}$, Haichao $\mathrm{LI}^{3}$, Shangming JIANG ${ }^{4}$, \\ Rongxing $\mathrm{ZHOU}^{1,2}$, Liangguang $\mathrm{ZHOU}^{1,2}$ \\ 1 School of Civil Engineering, Hefei University of Technology, Hefei 230009, China; \\ 2 Institute of Water Resources and Environmental Systems Engineering, Hefei University of Technology, Hefei \\ 230009, China; \\ 3. Interdisciplinary Centre for River Basin Environment, University of Yamanashi, Kofu 400-8510, Japan \\ 4 Key Laboratory of Water Conservancy and Water Resources of Anhui Province, Water Resources Research Institute \\ of Anhui Province and Huaihe River Commission, Ministry of Water Resources, Hefei 230088, China \\ *Correspondence: ycui@hfut.edu.cn; Tel.: +86-0551-62903357
}

\begin{abstract}
Drought risk management can effectively reduce drought losses and improve drought resistance capability, of which drought risk assessment is the core issue. This study evaluated the agricultural drought risk in Huaibei Plain of Anhui Province in China by the approach of constructing drought loss risk curves and risk distribution maps. The results showed that: 1) The drought events that occurred in northern regions (Huaibei and Suzhou) were with the characteristics of high-frequency and low-intensity, while in southern regions (Huainan and Bengbu), the occurring characteristics were lowfrequency, high-intensity, and long-duration. 2) Without irrigation, Fuyang was the high-risk region with more than $80 \%$ potential yield loss rate, while Huainan was the relatively low-risk area with a potential yield loss of $50 \%$. 3) Irrigation had a significant effect on reducing drought risk loss, while the efficiency was influenced by the spatio-temporal distribution of precipitation. The irrigation scheme in study area still remains to be optimized based on the characteristics of precipitation and crop growth. This study established and practiced a quantitative framework for regional drought risk assessment by creating drought risk curves and risk maps, which have significant value in improving the regional agricultural drought risk management level.
\end{abstract}

Keywords: Drought hazard; Risk curves; Risk maps; Crop growth simulation; Huaibei Plain of Anhui Province

\section{Introduction}

Drought disaster is one of the most complex natural disasters with high occurring frequency, long duration, and wide affecting range (Bahrami et al., 2018). Under the background of global climatechanging and water shortages, drought disaster has severely disrupted the ecological environment and agricultural production (Fontaine et al., 2009). Worldwide, the drought-affected area has expanded more than twice, and grain production has dropped by 9-10\% since 1970 (Crocetti et al., 2020; Lesk et al., 2016). China, an agricultural country with frequent natural disasters, is located in the East Asian monsoon region. There were more than $70 \%$ of natural disasters were meteorological disasters, moreover, among the meteorological disasters losses, more than $50 \%$ were caused by drought, especially in agriculture (Yao, 2020). For nearly 70 years, the annual agricultural drought-affected area 
was over 2.06 billion $\mathrm{hm}^{2}$, and the grain loss was over 16.30 billion $\mathrm{kg}$ (Zhang, F. et al., 2019). With population increasing and rapid urbanization, drought disaster has become a major threat to social development.

Drought risk evaluation is the core issue of risk management (Jin et al., 2016; Zhao et al., 2020). In a specific region, drought risk assessment refers to describing and quantifying the possible losses caused by a drought event with a specific intensity (Dabanli, 2018; Fei, 2014). The most widely used assessment methods including:

(1) Methods based on statistical theory (Yin et al., 2015). These methods describe the drought risk through the possible recurrence of drought events (calculated by historical data series, including meteorological data, drought loss data) (Qu, 2018). For example, Santos et al. (2011) calculated the drought reappearance periods in Portugal and plotted the intensity distribution maps of drought events. Hao and Aghakouchak (2014) used information diffusion theory to construct a comprehensive index (including drought-affected areas and losses), then evaluated the regional drought risk at county scale in China. The above methods have simple calculation and flexible spatiotemporal scales, however, the results can not reflect the formation process of drought disaster, and the evaluation accuracy is more affected by the data (Jin et al., 2016).

(2) Methods based on natural disaster risk system theory (Shi et al., 2011). These methods describe the drought as a system combined with disaster-formative factors, disaster-bearing bodies, and the disaster-formative environment (Liu and Chen, 2020). According to the expression form, these methods can be divided into static indicators evaluation methods (Santos et al., 2011) and dynamic simulation evaluation methods (Sun et al., 2013). For example, Shahid and Behrawan (2008) established a comprehensive drought risk index based on precipitation, food production, and social conditions, then plotted the drought risk distribution map of western Bangladesh. Mehdikhani et al. (2016) constructed the crop drought loss risk curves based on neural networks, and analyze the agricultural drought risk. In the static indicators evaluation approaches, the selection of indicators and corresponding weights may not objective, and the evaluation results are presented as comprehensive value, which cannot reflect the drought formation mechanism $(\mathrm{Qu}, 2018)$. The scenario simulation method can describe the mechanism and interaction process of drought risk system elements, which is an emerging trend in the drought risk assessment (Ali et al., 2020; Hao et al., 2012).

Drought risk curves can reflect the process that the disaster-formative factors' severity transmitted into final loss through the disaster-bearing bodies (including sensitivity and resistance ability) (Fei, 2014; Jin et al., 2016). Previous studies about agricultural drought risk evaluation mostly establish the relationships between drought frequency and crop potential yield loss (Mehdikhani et al., 2016; Sun et al., 2013). The evaluation objective was just crop yield only, which cannot reflect the accumulated negative effect of drought and the positive effect of drought-resistance measures. In this study, we described the disaster intensity by drought-occurring frequency (reappearance period), assumed the drought-resistance capability by irrigation, and simulated the crop response process based on DSSAT. Finally, according to the above contents, we quantified the agricultural drought loss risk in the study area by constructing crop drought loss risk curves and distribution maps. The detailed research contents are as follows:

(1) Analysis of drought-formative factors intensity. This part included drought indicator selection, drought events identification, and drought-occurring frequency calculation (Spinoni et al., 2014; Zhou et al., 2014). At present, widely used drought indicators including precipitation-based indexes, like Precipitation Anomaly (Henry, 1907) and Standard Precipitation Index (McKee et al., 1993), 
evapotranspiration-based indexes, like Crop Moisture Index (Palmer, 1968) and K Drought Index (Wang et al., 2007), and remote sensing-based indexes, like Vegetation Condition Albedo Drought Index (Ghulam et al., 2007) and Normalized Difference Vegetation Index (Yuhas and Scuderi, 2009), etc. After determining the drought index, the drought events can be described by severity and duration. The run theory is the commonly used identification method, which can quantify the drought events by setting thresholds (Mishra and Singh, 2011). To reflect the above drought characteristics, the Copula functions were widely used for calculating the joint distribution of severity and duration (Zhou et al., 2014). Rain-fed agriculture is the main crop production mode of China. SPI (Standard Precipitation Index) is a typical precipitation-based index that is widely applied in drought identification, and can reflect the intensity and duration of drought with a flexible time scale (Wu et al., 2005). Therefore, this study calculated the monthly SPI as a drought indicator, identified drought events based on run theory, and obtained the occurring frequency by using the Copula function.

(2) Simulation of drought-affected bodies' responsiveness. In agricultural drought risk system, field experiment is an effective method to analyze the loss sensitivity of crops, but the physical experiments are costly and time-consuming (Cui et al., 2019). In recent studies, the crop growth simulation models that integrated multi-disciplinary knowledge (crop science, meteorology, and computer technology) have become the new focus (Siad et al., 2019). The commonly used crop growth simulation models include the AquaCrop (Crop-water productivity model, developed by the Food and Agriculture Organization of the United Nations) (Hsiao et al., 2009), EPIC (Erosion Productivity Impact Calculator, developed by the United States Department of Agriculture) (Riboli and Kaaks, 1997), and the DSSAT (Decision Support System for Agrotechnology Transfer, developed by the International Benchmark Sites Network for Agrotechnology Transfer) (Jones et al., 2003), etc. DSSAT can simulate the daily physiological growth of crops based on crop genetic characteristics, soil, climate, and field management measures. Compared with other models, DSSAT has unique advantages in seasonal climate change simulation, field management assessment (Jones et al., 2003), farming optimization (Saddique et al., 2020), and water regulation (Malik and Dechmi, 2019), etc. However, the application of DSSAT in drought risk assessment and management is still seldom. Therefore, this study will use DSSAT to simulate the yield formation process of the crop in agricultural drought system, to evaluate drought risk based on crop drought response mechanism.

(3) Simulation of drought resistance capability. Drought resistance capability refers to the drought disaster system's ability to withstand stress and reduce losses (Hsiao and Acevedo, 1974; Prabnakorn et al., 2019). In agricultural drought system, commonly drought-resistant measures include agricultural hydraulic engineering, crop genetic improving, and irrigation optimizing (Carrao et al., 2016), etc. This study simulated the drought-resistance scenario by setting different irrigation levels, due to its flexibility and practicality.

Soybean is a typical gain and economical crop that originated in China (Zhang, T. et al., 2019). Huaibei Plain of Anhui Province has mild climates, the average temperature is $14-17^{\circ} \mathrm{C}$, the annual precipitation is $800-1800 \mathrm{~mm}$, the annual sunlight hours is $2800-2500 \mathrm{~h}$, and the frost-free period is 200-250 $d$ (Zhang, T. et al., 2019). Moreover, Anhui Province is the third-largest soybean-producing region, accounting for $6 \%$ (more than 1000 million $\mathrm{kg}$ ) of the total soybean output in China (Hu and You, 2015). The agricultural water demand in Anhui Province is mainly from the precipitation in the flood season (from June to September). High temperature and drought caused by the summer Pacific subtropical high are the main reasons for summer crops (maize, soybean, cotton, etc.) yield reduction (Fei, 2014). In recent 50 years, meteorological disasters have shown an expanding trend in Anhui 
Province, and the drought disaster accounted for over 32\% (Zhai, 2007). Scientifically quantify and evaluate the drought loss risk in Huaibei Plain of Anhui Province will contribute to reducing agricultural losses and protecting regional food security.

Based on the above background, this study analyzed the spatio-temporal distribution of drought events that occurred in Huaibei Plain of Anhui Province. Then adjusted and verified the simulation cultivar specific parameters of local soybean based on pits experiments. At last, established the drought loss risk distribution maps and risk curves by using DSSAT-GROPGRO-Soybean model. This study aimed to provide theoretical basis and practical approach for local drought loss risk assessment.

\section{Methods and materials}

This study constructed soybean drought loss risk curves and risk distribution maps (based on precipitation data, soybean pits experiments, and DSSAT simulation) to assess the agricultural drought loss risk in Huaibei Plain of Anhui Province. The specific research processes were as the following steps (Figure 1):

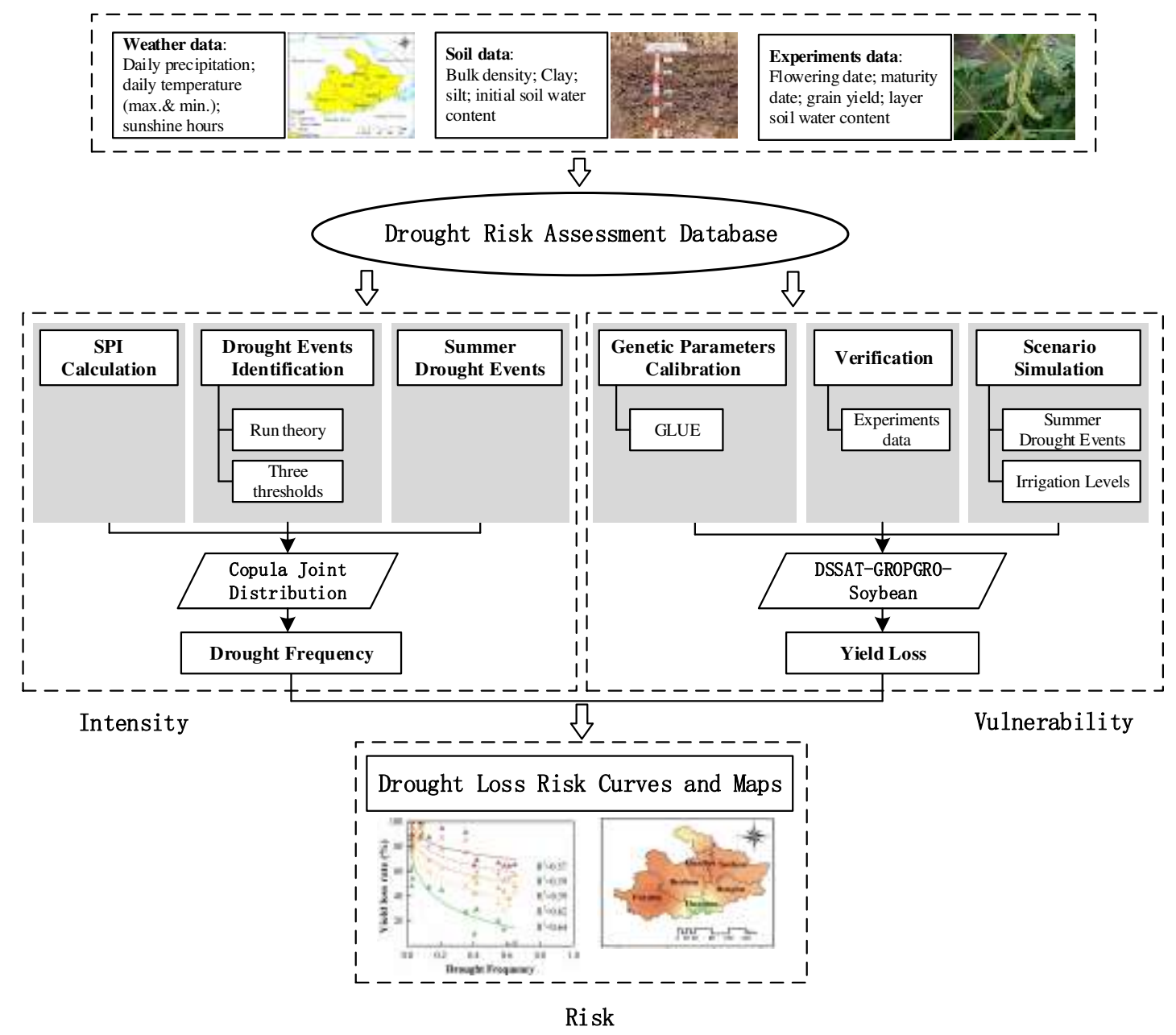

Figure 1. Flowchart of establishing drought loss risk curves and maps.

(1) Establishing database: Including daily weather data(from the national meteorology stations in study region during 1955-2012), soil data (from the experiment station), and field management data 
(from soybean pits experiments during 2016-2017).

(2) Identifying the intensity of drought events: Calculated the monthly SPI (Elkollaly et al., 2018) (during 1955-2012) in the study area. Then identified drought events (including severity and duration) based on run theory (Yevjevich, 1969) and three-threshold method (Zhou et al., 2014). The occurring frequency and reappearance periods of these events was calculated by the Copula function (based on joint probability distribution of severity and duration) (Zhou et al., 2014).

(3) Simulating the drought-caused yield loss: Calibrated the cultivar parameters of DSSATCROPGRO-Soybean mode by using Generalized Likelihood Uncertainty Estimation method (Salmeron et al., 2017), and verified the model by comparing the simulated and observed results (soybean experiments in 2016 and 2017). Then, weather data in drought years (identified in step 1.) and several irrigation levels were set as input variables, the physiological growing and yield formation were simulated on a daily basis. The drought yield loss was calculated by comparing with the simulated results under average weather conditions.

(4) Assessing the regional drought loss risk: Established drought risk curves about "drought frequency-yield loss-irrigation levels" and constructed risk distribution maps under different reappearance periods. Then compared and analyzed the distribution difference in study area.

\subsection{Study area and data sources}

The Huaibei Plain of Anhui Province is located in the northern Anhui Province, China. There are 6 sub-regions in research area, including Bengbu, Fuyang, Suzhou, Huaibei, Huainan, and Bozhou. The weather data, soil characteristics and field management data were acquired from Chinese meteorological stations and the Xinmaqiao Farmland Irrigation and Drainage Experiment Station (Figure 2).

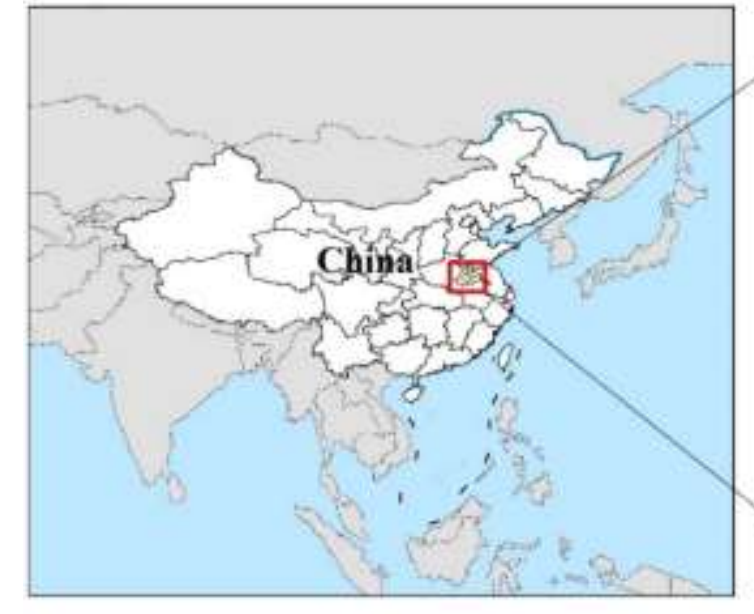

Figure 2. Geographic location of the Huaibei Plain of Anhui Province.

The daily weather data used for drought events identification and crop growth simulation were acquired from Chinese meteorological stations, including daily maximum and minimum air temperatures $\left({ }^{\circ} \mathrm{C}\right)$, precipitation $(\mathrm{mm})$, relative humidity and solar radiation (calculated by Angstrom function) $\left(\mathrm{MJ} / \mathrm{m}^{2}\right)$ (Angstrom, 1924) during 1965-2012. The weather data used for model calibration and verification were acquired from Xinmaqiao Farmland Irrigation and Drainage Experiment Station, the Anhui and Huaihe River Institute of Hydraulic Research in Bengbu City, Anhui Province in 2016 
and 2017. The information of meteorological stations and experimental station was shown in Table 1.

Table 1 Geographic information of meteorological station and experimental station.

\begin{tabular}{llll}
\hline Name & Long. $\left({ }^{\circ} \mathrm{E}\right)$ & Lat. $\left({ }^{\circ} \mathrm{N}\right)$ & ASL.(m) \\
\hline Huaibei(Meteor.) & 116.33 & 34.42 & 43.2 \\
Bozhou(Meteor.) & 115.77 & 33.87 & 37.7 \\
Suzhou(Meteor.) & 116.98 & 33.63 & 25.9 \\
Fuyang(Meteor.) & 115.82 & 32.92 & 30.6 \\
Huainan(Meteor.) & 116.78 & 32.55 & 22.7 \\
Bengbu(Meteor.) & 117.38 & 32.95 & 18.7 \\
Xinmaqiao(Exper.) & 117.36 & 33.15 & 18.0 \\
\hline
\end{tabular}

The typical soil in Huaibei Plain is Lime concretion black soils. The characteristics of soil were measured in the experimental station. The soil saturated water capacity, field capacity, wilting point, $\mathrm{pH}$, and organic matter content are shown in Table 2 . The soil bulk density, clay content, silt content and initial soil water content are shown in Table 3.

Table 2 Initial soil properties for simulation.

\begin{tabular}{ll}
\hline Soil characteristics & Value \\
\hline Saturated water capacity (\%) & 41.4 \\
Field capacity $(\%)$ & 28.0 \\
Wilting point (\%) & 11.0 \\
$\mathrm{pH}$ & 7.5 \\
Organic matter content $(\%)$ & 1.0 \\
\hline
\end{tabular}

Table 3 Initial soil properties (in layers) for simulation

\begin{tabular}{ccccc}
\hline Soil layer & $\begin{array}{c}\text { Bulk density } \\
\left(\mathrm{g} / \mathrm{cm}^{3}\right)\end{array}$ & $\begin{array}{c}\text { Clay } \\
(\%)\end{array}$ & $\begin{array}{c}\text { Silt } \\
(\%)\end{array}$ & $\begin{array}{c}\text { Initial soil water content } \\
\left(\mathrm{cm}^{3} / \mathrm{cm}^{3}\right)\end{array}$ \\
\hline $0-10 \mathrm{~cm}$ & 1.33 & 25 & 70 & 0.25 \\
$10-20 \mathrm{~cm}$ & 1.56 & 30 & 67 & 0.28 \\
$20-30 \mathrm{~cm}$ & 1.61 & 23 & 73 & 0.26 \\
$30-40 \mathrm{~cm}$ & 1.55 & 25 & 71 & 0.28 \\
\hline
\end{tabular}

The soybean pits experiments were conducted in 2016 and 2017 (from June to September), and the experiments data were used for calibrating and verifying the DSSAT-GROPGRO-Soybean model. The experimental soil was Lime concretion black soils, and the experimental soybean cultivar was "Zhonghuang-13". Previous studies have shown that the experiments data without water shortage may improve the calibration accuracy (Ziaei and Sepaskhah, 2003), and the study region was a typical rain-fed farming area. Therefore, this study conducted full irrigation and rain-fed experiments in 2016 and 2017, respectively (Wei et al., 2021). There were three replications for each experiment and all samples were managed in the same way. The sowing date, harvesting date, sowing depth, and planting density were shown in Table 4 . The growth stages division were shown in Table 5. 
Table 4 Planting management information in 2016 and 2017.

\begin{tabular}{lll}
\hline Planting management & 2016 & 2017 \\
\hline Sowing date & Jun.14 & Jun.9 \\
Harvesting date & Sep.15 & Sep.21 \\
Sowing depth $(\mathrm{cm})$ & \multicolumn{2}{c}{5} \\
Plant spacing $(\mathrm{cm})$ & \multicolumn{2}{c}{6} \\
Row spacing $(\mathrm{cm})$ & \multicolumn{2}{c}{40} \\
Planting density $\left(1000\right.$ plants $\left(\mathrm{hm}^{2}\right)$ & 300 \\
\hline
\end{tabular}

Table 5 Division of soybean growth stages in 2016 and 2017.

\begin{tabular}{cccc}
\hline Stages & 2016 & 2017 & Description \\
\hline I & Jun.14-Jul.10, & Jun.9-Jul.5, & Seeding period. \\
& $26 d$ & $26 d$ & \\
II & Jun.11-Jul.24, & Jun.6-Jul.24, & Branching period. \\
& $13 d$ & $18 d$ & \\
III & Jul.25-Aug.14, & Jul.25-Aug.9, & Flowering and pod-setting period. \\
& $20 d$ & $15 d$ & \\
IV & Aug.15-Sep.15, & Aug.10-Sep.21, & Pod-filling period. \\
& $31 d$ & $42 d$ &
\end{tabular}

\subsection{Drought frequency and reappearance periods calculation}

\subsubsection{SPI}

The meteorological drought is a regional phenomenon in which the precipitation was significantly lower than normal during a specific period (Pinkayan, 1966). Huaibei Plain of Anhui Province is a typical rain-fed farming region. The continual insufficient precipitation is the major inducing factor of agricultural drought. SPI (McKee et al., 1993) was a typical drought index that can reflect the climate and precipitation anomalies under different time scales and was adaptable in Huai River Basin (Li et al., 2021). Considering the growth cycle of soybean is about four months, this study used monthly SPI for identifying drought events and calculating drought frequency. The monthly SPI was calculated as following steps: Defining the long-term monthly precipitation from Gamma distribution. Then, calculated the cumulative probability of monthly precipitation and transformed the cumulative probability into standard normal distribution. The results were the SPI values. In addition, a smaller SPI value indicates a severer drought.

\subsubsection{Run theory}

A drought event can be described as a process with severity and duration. The run theory is one method that can analyze the long-term data series (including disaster events series) (Yevjevich, 1969). The drought events were identified by monthly SPI and three thresholds (including occurring threshold $R_{1}$, eliminating threshold $R_{2}$, and merging threshold $R_{3}$ ) (Fei, 2014; Wei et al., 2021), and the identification process can be shown as following steps (Figure 3): Firstly, select the initial drought 
process of which the drought index (monthly SPI) is less than $R_{1}(a, b, c, e, f$ and $h$ ). Then, eliminate the drought processes with a unit time (one month) and the drought index greater than $R_{2}(a)$. For the adjacent drought processes with a unit time interval, if the interval drought index was less than $R_{3}$, they will be merged into one process $(c-d-e)$, otherwise $(g)$, divided into two independent processes $(f$, $h$ ). The drought duration is the total unit time of the drought process, and the drought intensity is the cumulative value of SPI.

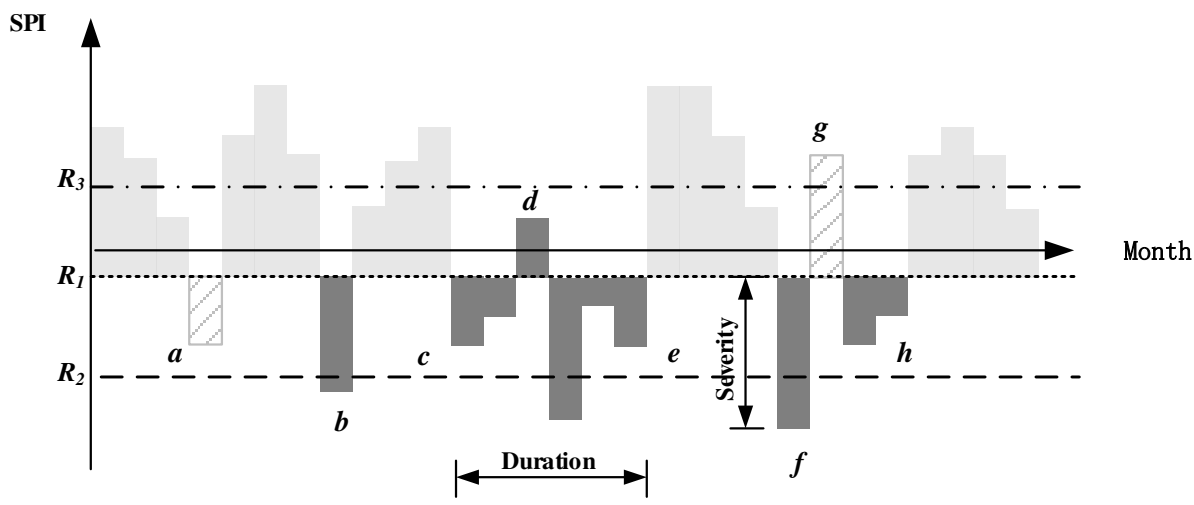

Figure 3. Identification process of drought events.

\subsubsection{Drought frequency and reappearance periods}

The intensity of drought-formative factors was expressed by drought-occurring frequency. According to previous researches (Lee et al., 2013), the marginal distribution of duration and severity can be expressed by exponential and gamma function, respectively. The parameters of distribution functions were calculated by the maximum likelihood method (Wang et al., 2019b).

Copula functions can transform two one-dimensional marginal distributions into a joint probability distribution. They have diverse function structures (including Clayton function, Frank function, and Gumbel-Hougaard function), simple solving processes, and precise results (Wang et al., 2019a). Cumbel-Hougaard function can describe the upper tail correlation of data (Zhou et al., 2014), which was suitable for drought duration and severity. The parameters of copula function were estimated by the moments like method and the Kendall's $\tau$ (Masoliver, 2009). The GumbelHougaard function was shown as follows (Wei et al., 2021):

$$
C(u, v, \theta)=\exp \left\{-\left[(-\ln u)^{\theta}+(-\ln v)^{\theta}\right]^{\frac{1}{\theta}}\right\}
$$

where $u$ and $v$ are the marginal distribution of duration and severity, respectively, $\theta$ is the parameter calculated based on Kendall's $\tau$ (Masoliver, 2009):

$$
\begin{gathered}
\tau=1-\frac{1}{\theta} \quad, \theta \in[1, \infty) \\
\tau=2 \sum_{i<j} \operatorname{sgn}\left[\frac{\left(d_{i}-d_{j}\right)\left(s_{i}-s_{j}\right)}{N(N-1)}\right] \quad, i=1,2, \cdots, N
\end{gathered}
$$

where $d$ is the duration, $s$ is the severity, $N$ is the sample size and $s g n$ is a symbolic function (Fei, 2014): 


$$
\operatorname{sgn}=\left\{\begin{array}{cc}
1 & \left(d_{i}-d_{j}\right)\left(s_{i}-s_{j}\right)>0 \\
-1 & \left(d_{i}-d_{j}\right)\left(s_{i}-s_{j}\right)<0 \\
0 & \left(d_{i}-d_{j}\right)\left(s_{i}-s_{j}\right)=0
\end{array}\right.
$$

The joint occurring frequency and reappearance period for severity and duration can be described as (Fei, 2014; Shiau and Shen, 2001):

$$
\begin{gathered}
P(D>d, S>s)=1-F_{D}(d)-F_{S}(s)+F_{D, S}(d, s) \\
\mathrm{T}(D>d, S>s)=\frac{E(L)}{P(D>d, S>s)}=\frac{E(L)}{1-F_{D}(d)-F_{S}(s)+F_{D, S}(d, s)}
\end{gathered}
$$

where $F_{D}=u, F_{S}=v, E(L)$ is the expected value of the interval, $P(D>d, S>s)$ and the $\mathrm{T}(D>d, S>s)$ are the frequency and reappearance period of a specific drought events (duration longer than $d$, severity lager than $s$ ) respectively.

\subsection{CSP of DSSAT-GROPGRO-Soybean}

The response loss of drought-affected bodies was expressed by simulating soybean yield loss rate. The DSSAT defines Cultivar Specific Parameters (CSP) for different crop varieties (Jones et al., 2003). Users can construct specific crop growth models suitable for different regions and varieties based on experiments data (including weather data, field management data, crop growth observation data) (Keith and Andrew, 2014). Previous researches showed that there should be at least two cases of nonwater shortage treatment in experiments for model calibration and verification, respectively (Yao et al., 2020). Therefore, this study calibrated and verified the CSP of soybean (cv. Zhonghuang-13) in Huaibei Plain of Anhui Province based on the two-year pits experiments (fully irrigated experiment in 2016 and rain-fed experiment in 2017). The CSP for DSSAT-GROPGRO-Soybean model were shown in Table 6.

Table 6. CPS of Zhonghuang-13

\begin{tabular}{llc}
\hline GSP & Description & Calibrated values \\
\hline EM-FL & Time between plant emergence and flower appearance (photothermal days) & 18.0 \\
FL-SH & Time between first flower and first pod (photothermal days) & 10.0 \\
FL-SD & Time between first flower and first seed (photothermal days) & 11.0 \\
SD-PM & Time between first seed and physiological maturity (photothermal days) & 26.0 \\
FL-LF & Time between first flower and end of leaf expansion (photothermal days) & 19.0 \\
CSDL & Critical Short Day Length (h) & 12.3 \\
PPSEN & Slope of the relative response of development to photoperiod with time $(1 / \mathrm{h})$ & 0.2 \\
LFMAX & Maximum leaf photosynthesis rate $\left(\mathrm{mg} \mathrm{CO}_{2} / \mathrm{m}^{2}-\mathrm{s}\right)$ & 1.3 \\
SLAVR & Specific leaf area of cultivar $\left(\mathrm{cm}{ }^{2} / \mathrm{g}\right)$ & 389.4 \\
SIZLF & Maximum size of full leaf $\left(\mathrm{cm}^{2}\right)$ & 141.3 \\
WTPSD & Maximum weight per seed $(\mathrm{g})$ & 0.2 \\
SDPDV & Average seed per pod (seeds/pod) & 1.9 \\
\hline
\end{tabular}

The CSP were calibrated by the General Likelihood Uncertainty Estimation (GLUE) method (Keith and Andrew, 2014), and the calculation steps below (Yan, 2020):

Setting the prior distribution of CSP and randomly generated parameters sets (each sample set contained $13 \mathrm{CPS}$, and the number of samples sets were set to 10,000). Running the model several times to obtain the simulated output, and computing the likelihood value between simulated output 
and the measured value based on Gaussian likelihood function (Keith and Andrew, 2014):

$$
L\left(\theta_{i} \mid O\right)=\prod_{j=1}^{M} \frac{1}{\sqrt{2 \pi \sigma_{0}^{2}}} \exp \left\{-\frac{\left[o_{j}-Y\left(\theta_{i}\right)\right]^{2}}{2 \sigma_{0}^{2}}\right\}, \quad i=1,2,3 \ldots N
$$

where $\theta_{i}$ is the $i$ th sample set, $N$ is the total number of sample sets, $O$ is the measured values, $O_{j}$ is the $j$ th measured value, $M$ is the number of the measured value, $Y\left(\theta_{i}\right)$ is the simulated output based on $\theta_{i}, \sigma_{0}^{2}$ is the error variance between simulated values and measured values.

Then construct the posterior distribution of CSP (Yan, 2020):

$$
\begin{gathered}
\mu_{\text {post }}(\theta)=\sum_{i=1}^{N} p\left(\theta_{i}\right) \cdot \theta_{i} \\
\sigma_{\text {post }}^{2}(\theta)=\sum_{i=1}^{N} p\left(\theta_{i}\right) \cdot\left(\theta_{i}-\mu_{\text {post }}\right)^{2}
\end{gathered}
$$

where, $\mu_{\text {post }}(\theta)$ and $\sigma_{\text {post }}^{2}(\theta)$ are the mean value and variance of posterior distributions of CSP, respectively, $N$ is the total number of sample sets, $p\left(\theta_{i}\right)$ is the likelihood weight of the $i$ th parameter set (Keith and Andrew, 2014):

$$
p\left(\theta_{i}\right)=\frac{\left(\theta_{i} \mid Y\right)}{\sum_{i=1}^{N} L\left(\theta_{i} \mid Y\right)}
$$

where $L\left(\theta_{i} \mid Y\right)$ is the likelihood value of the parameter set $\theta_{i}, \mathrm{Y}$ is the corresponding observed value.

Finally, a set of CSP with the smallest error between simulated outputs and observed values were selected, and used for simulating the crop growth process under different scenarios.

\subsection{Irrigation simulation}

In this study, the drought resistance capability was simulated by setting irrigation schemes. According to previous researches (Cui et al., 2019; Wei et al., 2021) and historical experiments in the experimental station, there were five irrigation treatments (I1-I5, with different monthly irrigation quotas) and one rain-fed treatment (RF) were conducted for simulating the drought resistance capability (Table 7).

The crop drought loss rate was calculated based on the irrigation treatments as follows (Wei et al., 2021):

$$
Y L_{i, j}=\frac{S Y_{R F}-S Y_{i, j}}{S Y_{R F}} \times 100 \%
$$

where $Y L_{i, j}$ is the yield loss rate(with the $i$ th irrigation treatment in $j$ year), $S Y_{R F}$ is the simulated yield with treatment $R F, S Y_{i, j}$ is the simulated yield under $i$ th irrigation treatment in $j$ year.

Table 7 Irrigation schemes of simulation experiment

\begin{tabular}{cccccl}
\hline \multirow{2}{*}{ Irrigation levels } & \multicolumn{3}{c}{ Monthly irrigation quota $(\mathrm{mm})$} & \\
\cline { 2 - 5 } & Jun. & Jul. & Aug. & Sep. & Irrigation schemes \\
\hline I1 (0\%) & 0 & 0 & 0 & 0 & With drought year weather data and irrigation. The irrigation \\
I2 (25\%) & 0 & 12 & 12 & 0 & was implemented once every two weeks when supplemental \\
I3 (50\%) & 0 & 23 & 23 & 0 & irrigation was needed, with half of the monthly irrigation \\
I4 (75\%) & 0 & 34 & 34 & 0 & quota. \\
I5 (100\%) & 0 & 45 & 45 & 0 & \\
RF & 0 & 0 & 0 & 0 & With average weather data and no irrigation \\
\hline
\end{tabular}




\section{Results and Discussion}

\subsection{Statistical characteristics of historical drought events}

\subsubsection{Severity and duration}

To analyze the drought events distribution in Huaibei Plain of Anhui Province, this study converted the long-term precipitation data into monthly SPI (during 1955-2012). Then identified the drought events based on the run theory and three-threshold method (including occurring threshold $R_{1}$, eliminating threshold $R_{2}$, and merging threshold $R_{3}$ ). According to previous researches and specifications (Fei, 2014; Wei et al., 2021), the thresholds $R_{1}, R_{2}$, and $R_{3}$, were set to $0,-0.5$ and -1 , respectively.

The drought events and corresponding statistics were shown in Table 8. The spatial distribution of historical drought-occurring times, average duration, and average intensity were shown in Figure 4. The total occurring times of drought events during 1955-2012 in Huaibei Plain of Anhui Province was decreasing from north to the south (Huaibei suffered 99 drought events, and Huainan suffered 85 events). About the average drought severity, the maximum was appeared in Huainan (1.45), and the minimum was appeared in Huaibei (1.27), which showed a trend of increasing from north to south, but with little difference of each sub-region. The average duration also showed a higher value in southern regions (1.87 months in Huainan, and 1.74 months in Suzhou). Overall, the moderate drought events with short duration happened rather often in study area, and the northern regions may suffer more severe drought events.

The longest duration of drought events of each sub-region was similar (ranged from 6 months to 7 months), but the highest severity differed greatly. The severest drought events of Huainan was occurred during March-to-September in 2001, while in Bozho, the maximum severity appeared during December 1967-to-July 1968. Moreover, the severest drought events in other regions mainly occurred in 1966, 1967, and 2001, which were the typical drought years in Huaibei Plain of Anhui Province (Zhai, 2007). According to historical references (Zhai, 2007), there was a spring-to-autumn continuous drought occurred in Huaibei Plain, and the precipitation during August-October was less than $100 \mathrm{~mm}$. During July-to-October in 1967, the precipitation of Huai River Basin was reduced by 40\%-70\%, and the temperature was $2-3.5^{\circ} \mathrm{C}$ higher over the same period of years. The autumn crops in Huaibei Plain suffered severe drought (the total precipitation during the crop growth period was lower than evaporation by $600-800 \mathrm{~mm}$ ). Droughts also occurred during June-to-September in 2001. The abnormal precipitation in Anhui province caused a reduction of streamflow with $90 \%$ in Huai River. The disaster-bearing area was more than 1.87 million $\mathrm{hm}^{2}$.

Table 8 Statistical results of drought characteristics in Huaibei Plain of Anhui Province

\begin{tabular}{ccccccc}
\hline Sub-region & Occurring times & Av. severity & $\begin{array}{c}\text { Av. Duration } \\
\text { (months) }\end{array}$ & $\begin{array}{c}\text { Max. duration } \\
\text { (months) }\end{array}$ & Max. severity & Data \\
\hline Huaibei & 99 & 1.27 & 1.78 & 6 & 4.36 & 1966_May \\
Bozhou & 91 & 1.32 & 1.86 & 7 & 3.88 & 1967_Dec \\
Suzhou & 96 & 1.32 & 1.74 & 7 & 4.42 & 1967_Dec \\
Fuyang & 94 & 1.29 & 1.81 & 7 & 6.30 & 2001_Mar \\
Huainan & 85 & 1.45 & 1.87 & 7 & 7.50 & 2001_Mar \\
Bengbu & 93 & 1.32 & 1.87 & 7 & 4.87 & 1966_May \\
\hline
\end{tabular}



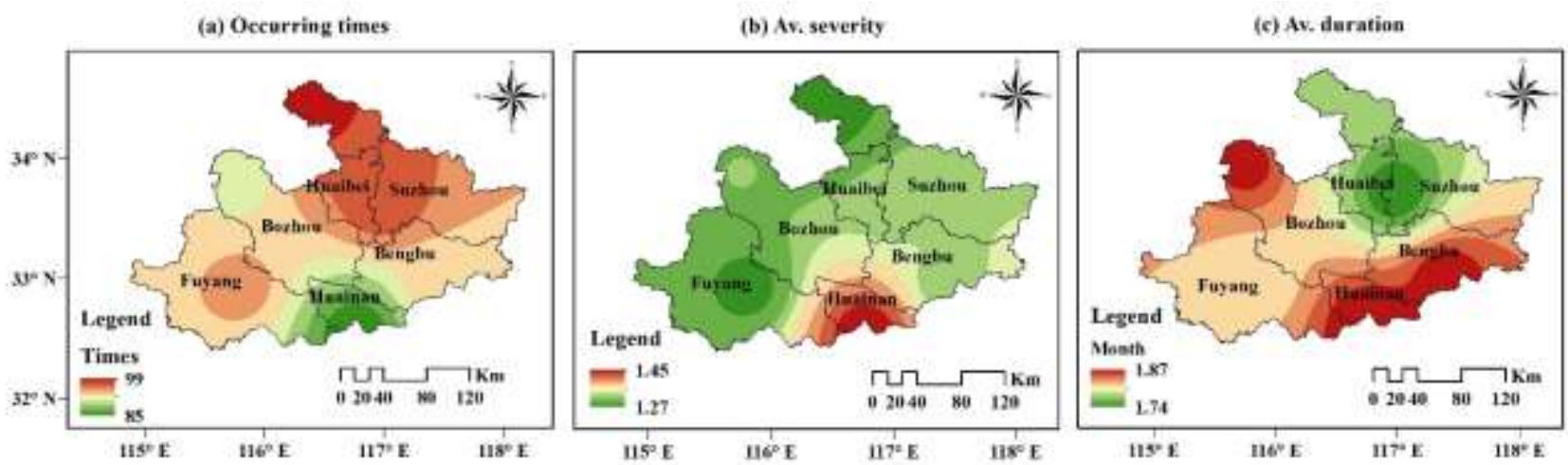

Figure 4. Spatial distribution of occurring times, intensity and duration in Huaibei Plain of Anhui Province

\subsubsection{Frequency and reappearance periods}

The joint cumulative probability distribution of drought events' duration and severity in each subregion were shown in Figure 5. The results indicated that the joint distributions calculated by the Gumbel-Hogaard copula function (Halwatura et al., 2015) were consistent with the empirical distribution results. The Kendall coefficients of drought severity and duration in Huaibei, Bozhou, Suzhou, Fuyang, Huainan, Bengbu regions were 0.36, 0.37, 0.43, 0.41, 0.45, and 0.44, respectively. With increasing drought severity or duration, the occurring probability was decreased.
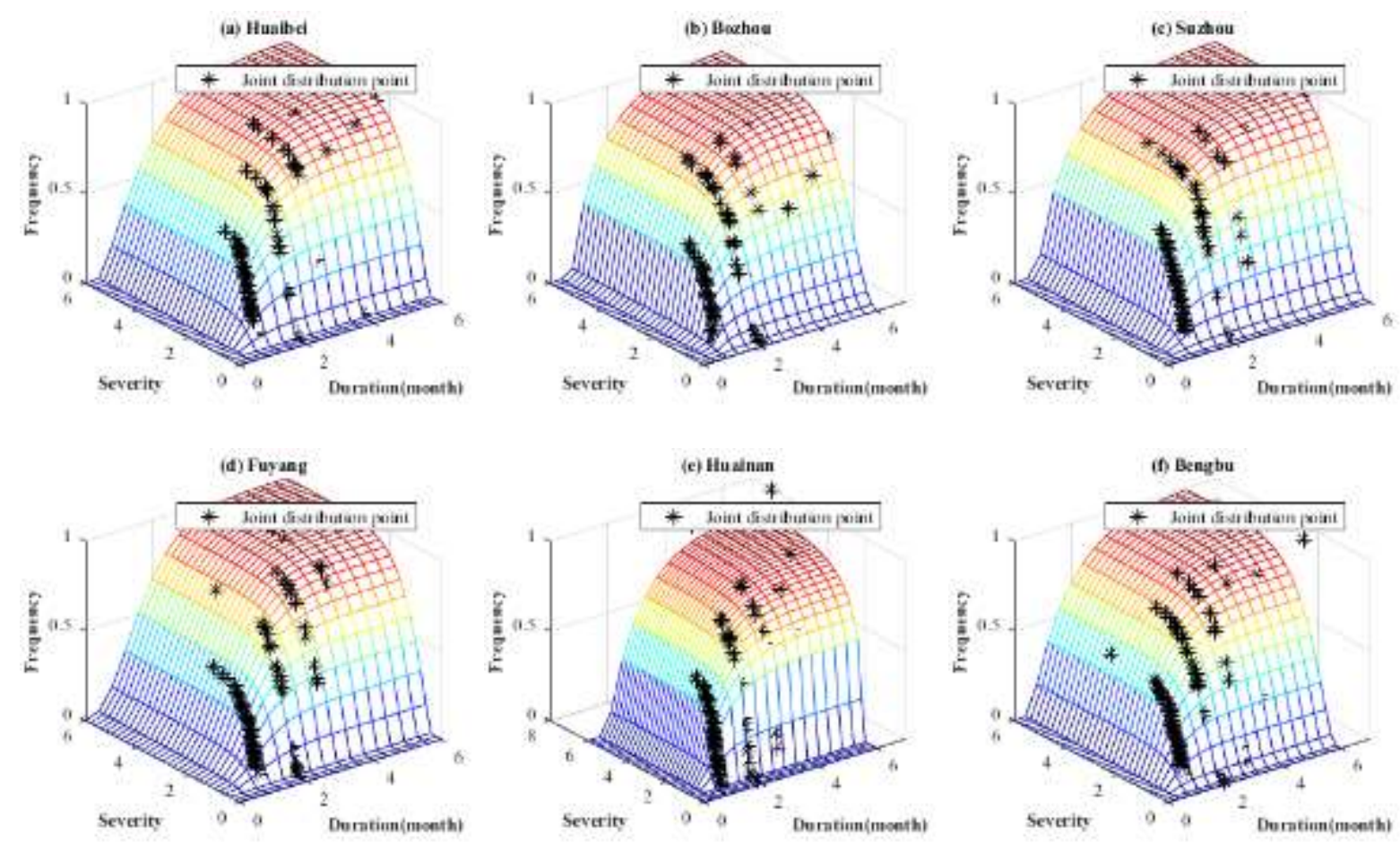

Figure 5. The joint cumulative probability distributions of drought duration and severity in six sub-regions. 

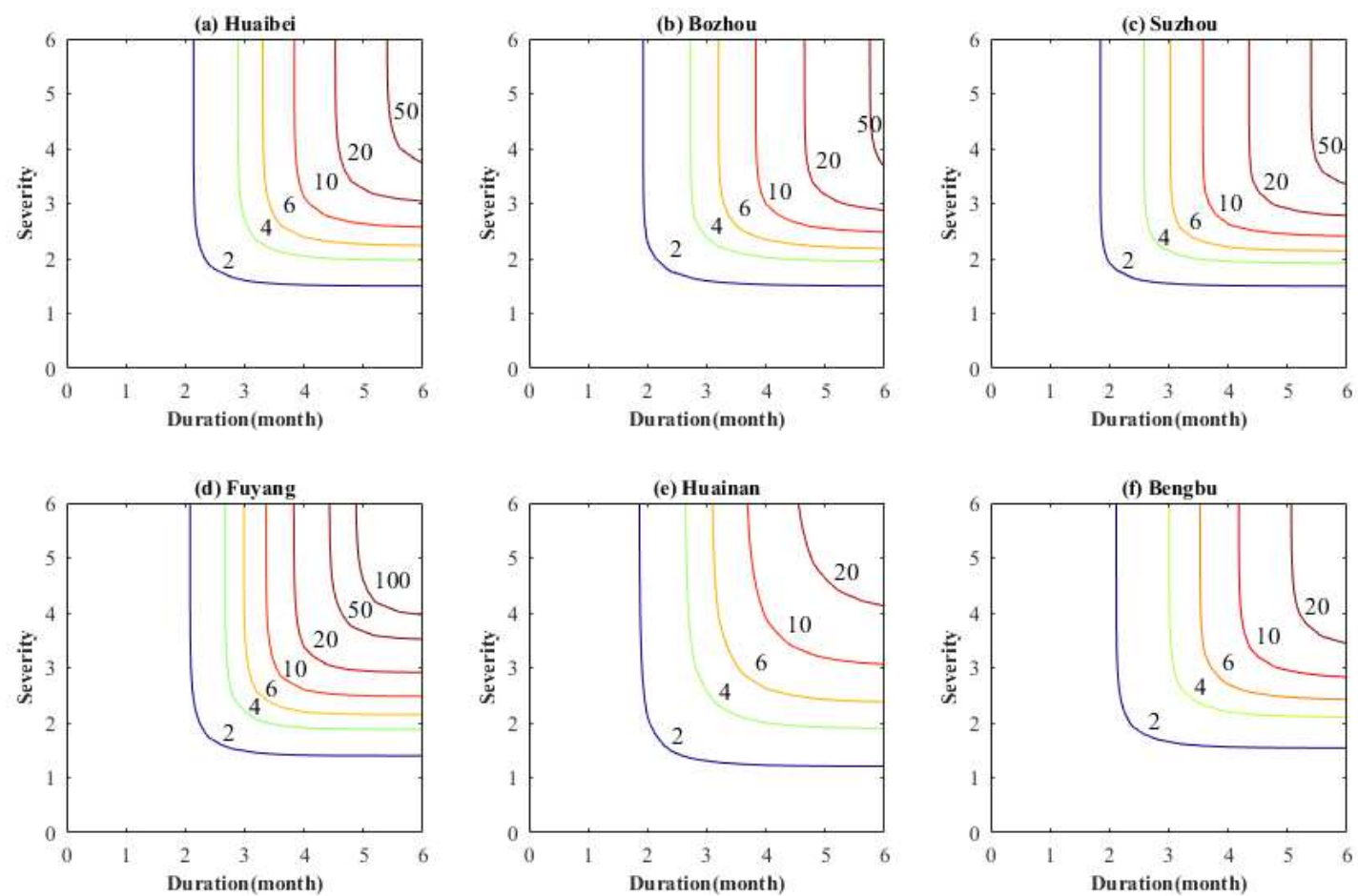

Figure 6. The reappearance periods of drought duration and severity in six sub-regions.

The average interval periods of drought events in Huaibei, Bozhou, Suzhou, Fuyang, Huainan, Bengbu regions were $6.90,7.58,7.19,7.34,8.11$, and 7.42 months, respectively, and the contours of the joint reappearance period were shown in Figure 6. The plots were useful in understanding the reappearance periods of drought events exceeding any severity and duration. In general, the reappearance periods of drought events increased with the increasing severity and duration. For each sub-region, the short-term moderate drought (severity less than 2, or duration less than 2 months) recurred frequently, with a 2-year reappearance period. The long-term severe drought events recurred most frequently in Huainan, where the drought events with severity of 5 or duration of 5 months recurred once in 20 years. This result was consistent with the statistics in Table 8 and Figure 4(The drought events of Huainan region has a lower occurring times but a higher average intensity) .In Fuyang, the same drought event recurred only once in 100 years, which indicated a lower occurrence probability of severe drought events in the location.

\subsection{Verification of Crop-Growing-Simulation model}

The simulation accuracy can be estimated by comparing the simulation and observed results about important time nodes and grain yield (Salmeron et al., 2017). The GSP of soybean cultivar "Zhonghuang-13" were calibrated based on the experimental data in 2017 (Wei et al., 2021; Yan, 2020) (Table 6). Then the calibrated GSP were used to simulate the growth of soybean in 2016 for verification. The simulated values and observed data were compared based on Absolute Relative Error (ARE) and shown in Table 9. The simulated phenological periods were closed to the observed results (within four days, $A R E$ less than 5\%), and the $A R E$ between simulated grain yield and actual one was within $7 \%$.

Moreover, previous researches showed the water-absorbing ability of soybean root was affected greatly by the soil moisture (Benjamin and Nielsen, 2006; Taiz and Zeiger, 2015). Therefore, the dynamic soil water content in $0-40 \mathrm{~cm}$ layer and top weights (leaves, stalks, and pods) were used to 
confirm the simulation accuracy of soybean physiological growth process (Figure 7). The comparison of simulation and observation values revealed a good agreement in the simulation process of crop growing or soil water changing, and all errors were less than $8 \%$. Therefore, the calibrated GSP were applicable for simulating the soil water changing and soybean growing.

Table 9 Simulated ( $\mathrm{Sim}$.) and observed (Obs.) results of soybean in 2016 based on the adjusted GSP.

\begin{tabular}{cccc}
\hline Comparison Target & Sim. & Obs. & ARE \\
\hline Flowering Date (Day after Planting) & 43 & 45 & $4.88 \%$ \\
\hline Maturity Date (Day after Planting) & 98 & 94 & $4.26 \%$ \\
\hline Grain Yield $\left(\mathrm{t} / \mathrm{hm}^{2}\right)$ & 3.09 & 3.31 & $6.40 \%$ \\
\hline Top weight (mean value, $\left.\mathrm{t} / \mathrm{hm}^{2}\right)$ & 3.73 & 3.65 & $7.6 \%$ \\
\hline Soil water content $(0-40 \mathrm{~cm}$, mean value) & 0.28 & 0.26 & $6.9 \%$ \\
\hline
\end{tabular}

(a) Top weight

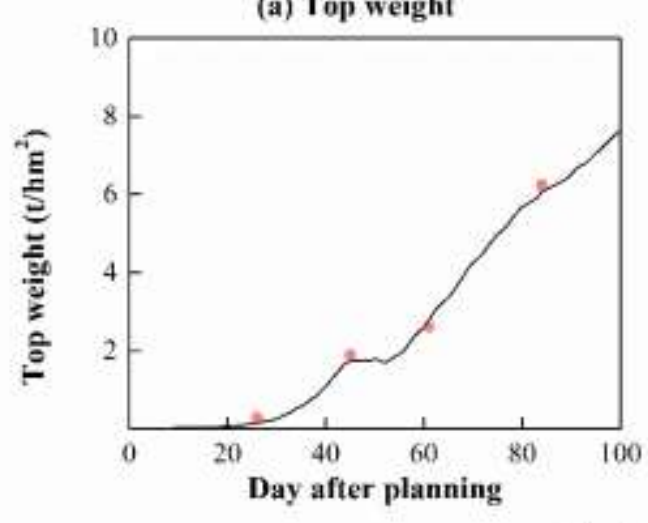

(b) Soil water content

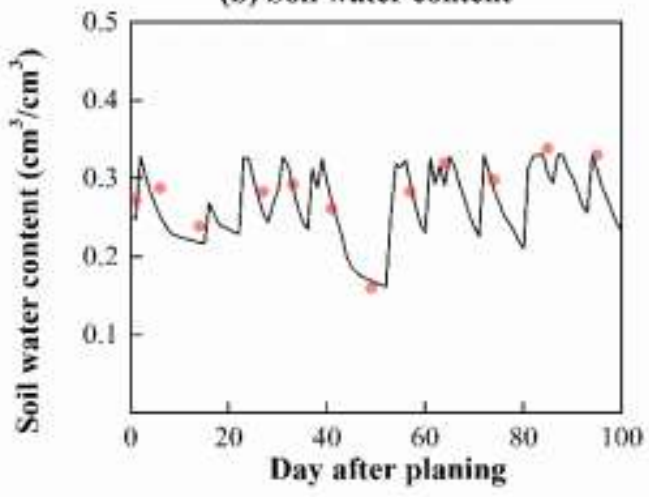

Observed

Figure 7. Simulated (Sim.) and observed (Obs.) value of top weight and soil water content of soybean

\subsection{Quantitative evaluation of drought loss risk}

\subsubsection{Risk curves}

Drought frequency was the occurring probability of a drought event with a specific severity and duration (Fei, 2014). The crop yield loss was the intuitive expression of drought loss risk (Jin et al., 2016). The irrigation was a typical drought resistance behavior (Cui et al., 2019). Therefore, the "drought frequency-soybean drought loss of yield-irrigation levels" curves (Figure 8) can reflect the process that the drought hazard intensity transmitted through the disaster-bearing bodies and caused losses (Jin et al., 2016).

The occurrence frequency of summer droughts (occurring during June-September) and corresponding yield losses (with irrigation) were fitted by semi-logarithmic function, the coefficients of determination $\left(R^{2}\right)$ were about $0.43-0.80$. The yield reduction rate of soybean decreased with the increasing of drought frequency or the improving irrigation levels. This phenomenon indicated that a severer drought event may cause a more adverse influence on soybean (with a specific irrigation scheme). While in a specific drought event, a more sufficient irrigation may reduce the loss of crop.

The soybean was a typical summer crop with high water requirement, which was sensitive to the shortage of moisture than other crops. According to the results, the yield loss of the rain-fed treatment without irrigation (I1) during drought years was higher in each sub-region. Irrigation can reduce the 
adverse effects of drought on crops, but the responses from the moderate droughts (with higher occurring frequency) were higher than that from extreme severe events (with lower occurring frequency). For example, the yield loss of I5 treatments in each sub-region was still more than $80 \%$ when an extreme drought event occurred (with the occurring frequency less than 0.05). Under the same conditions in moderate drought events, the yield increasing of crops with sufficient irrigation (I5) was responded to a $34.1 \%$ in Huaibei, $45.2 \%$ in Bozhou, 43.1\% in Suzhou, 50.1\% in Fuyang, 56.5\% in Huainan, and $33.5 \%$ in Bengbu.
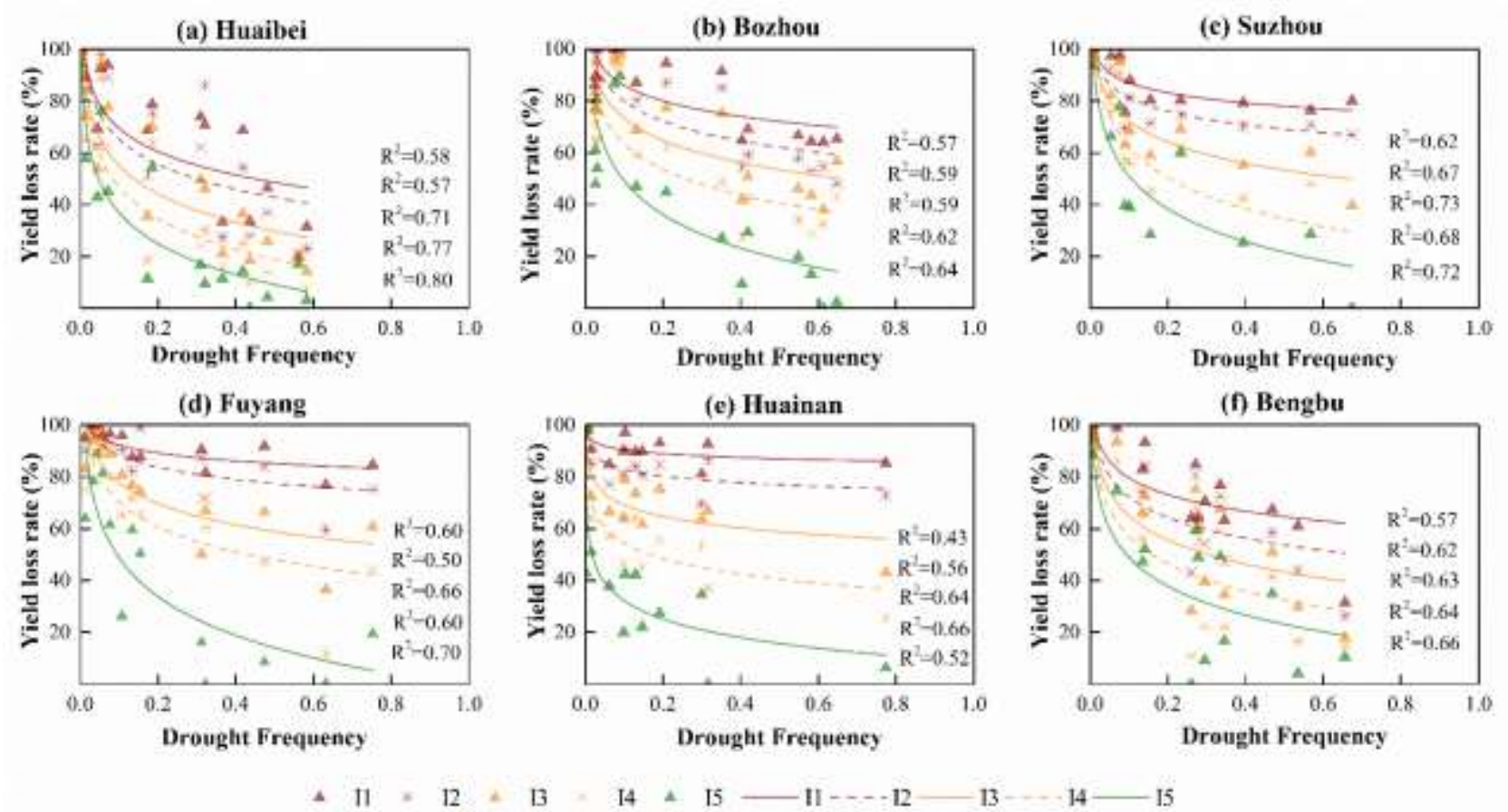

Figure 8. Soybean drought loss risk curves during 1955-2012 in sub-regions.

The above results were applicable to summer soybean in Huaibei Plain of Anhui Province. Additionally, when evaluating the agricultural drought loss risk in different seasons or using different summer crop cultivars, the results may differ due to the different water sensitivity of crops. Fei (2014) and Sun et al. (2013) constructed the spring drought loss risk curves based on wheat. Qu (2018) evaluated the summer agricultural drought loss risk in Liaoning Province, China based on risk curves and maize. These studies obtained different loss risk curves but the overall trends were similar. In summary, the crop drought loss risk curves were useful for analyzing regional drought hazards and optimizing irrigation schemes.

\subsubsection{Risk maps}

The drought loss risk distribution maps of Huaibei Plain in Anhui Province were plotted based on the above risk curves and the IDW (Inverse Distance Weight) interpolation method. Figure 9 reflected the possible loss of soybean in each sub-region with several irrigation levels (I1, I3, I5) when suffered different droughts (occurred every five years, ten years, twenty years, and fifty years), respectively. The yield loss represented the degree of drought loss risk. These distribution maps were useful for a macro-comparison of drought loss risk in study area, and provided a reference for making regional drought countermeasures. 
The possible yield losses of soybean without irrigation in drought years can present the potential drought loss risk in a specific sense. When suffered the once-in-five-years drought, Fuyang region showed a higher potential drought risk (with yield loss over $80 \%$ ), while Huaibei and Bengbu showed relatively lower risk (with yield losses from 50\% to 60\%). Moreover, when suffered drought events with longer reappearance periods, the potential drought risk of each sub-region also increased.

On the other hand, irrigation can reduce the drought loss risk by increasing the yield of soybean during drought years, but the response at each sub-region was different. For example, when suffered the once-in-five-years drought, the possible yield loss rate in Fuyang may drop to $45.1 \%$ with the assumed sufficient irrigation (I5), while in Huainan the response level was higher (dropped to 30.5\%). This phenomenon may be related to the spatio-temporal distribution of precipitation during different soybean growth periods. The water sensitivity of soybean was different in each stage (Cui et al., 2019), for instance, August was the flowering and pod-setting period of soybean in study area, the water shortage during this period may affect the production formation. In 1978, for example, the monthly precipitation of Huainan during June-September was 43, 73, 114, and $12 \mathrm{~mm}$, respectively, while in Fuyang the precipitation during the same period was 134, 65, 34, $10 \mathrm{~mm}$, respectively. The soybean yield in Fuyang with sufficient irrigation (I5) was only increased $11.2 \%$, while the same irrigation levels in Huainan lead to an increasing of $39.8 \%$. Fuyang had less precipitation during August, and the assumed irrigation was insufficient to eliminate the drought effects, which lead to a poor effect on risk reduction.

In general, the drought loss risk in study area was rising with the increasing of drought event reappearance period under the same irrigation level. While the drought loss decreased with the increasing of irrigation level under the same drought level (with the same reappearance period). In addition, the drought loss risk in northwestern regions was high than that in southern regions.

The above results were also consistent with previous researches. For example, Sun et al. (2012) divided the drought risk region in Anhui Province during 2000-2009 based on the disaster risk index, and founded that the drought hazard risk increased from southwest to northeast. Liu et al. (2013) established a comprehensive evaluation model in Huai River Basin based on natural hazard risk system theory. They pointed out that the southeastern region was the medium-risk area, while the northwestern region was the high-risk area. Zhang et al. (2014) studied the drought-occurring characteristics and the maize drought loss risk in Anhui Province during the maize growth period. Their results showed that the drought frequently occurred in the western region, and the western regions including Fuyang and Bozhou were severe-risk regions. Compared with our study, although the above researches existed differences in evaluation contents, the overall trend of results was consistent, and the differences were reasonable. For example, Sun et al. (2012) and Liu et al. (2013) considered the regional comprehensive drought risk as the evaluating objective, while this study was concentrated on agricultural drought risk. According to the relationship between different types of drought and the formation process of drought, there was a positive correlation between agricultural drought and other types of droughts (Fei, 2014), which validated the reasonableness of the assessment results in this study. Zhang et al. (2014) evaluated agricultural drought risk through the maize. Soybean and maize are both representative summer crops in Anhui Province. Maize has a higher drought resistance capacity, while soybean is more sensitive to water. Therefore, the soybean may suffer greater adverse effects than maize in the same drought event. Although using different crops for agricultural drought risk assessment, the evaluation results showed a relatively consistent trend, which indicated that the assessment model based on crop experiments and simulation was reasonable and effective. 
(a) RP_5 + IR_0\%

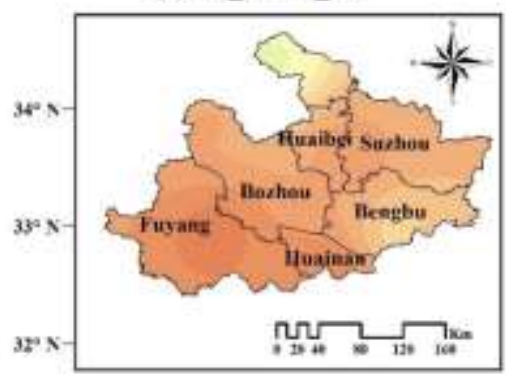

(d) RP_10+IR_0\%

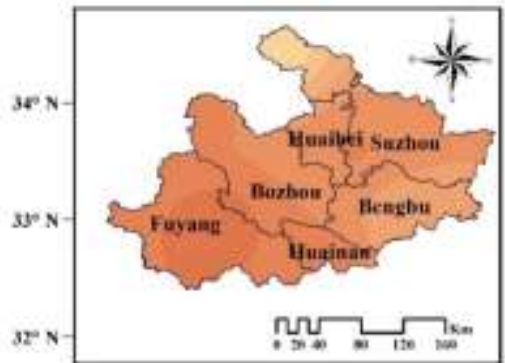

(g) RP_20+IR_ $0 \%$

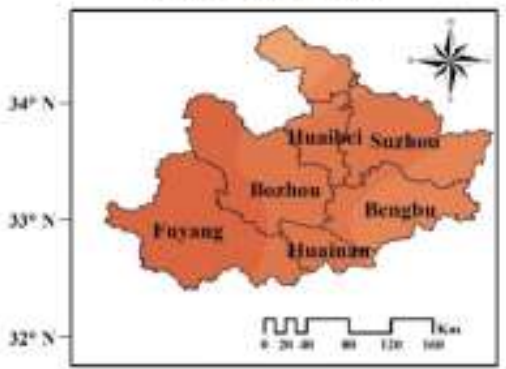

(j) RP_50+IR_0\%

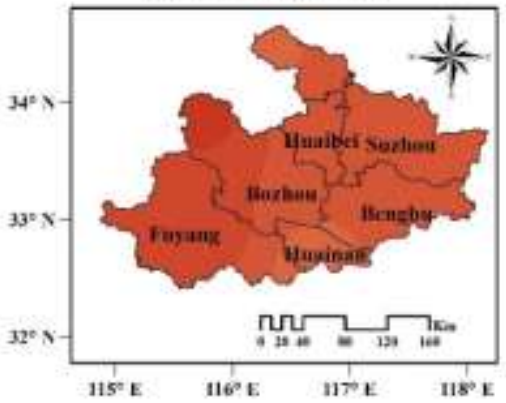

(b) RP_5 + IR_50\%

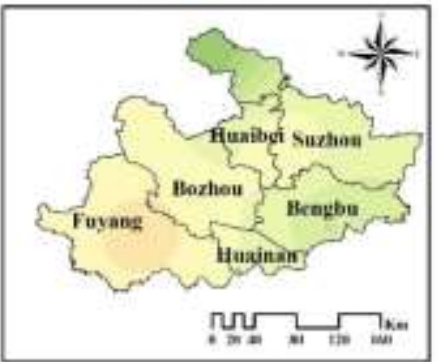

(e) RP_10+IR_50\%

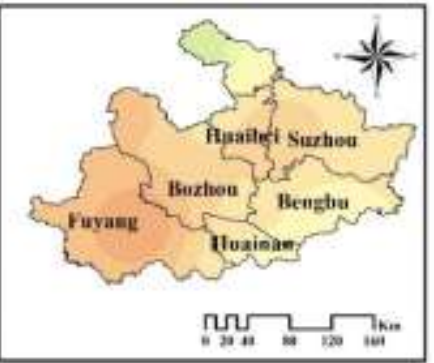

(h) RP_20 + IR_50\%

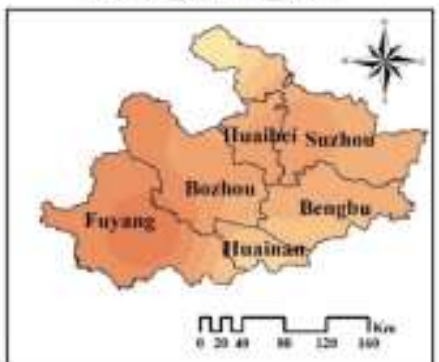

(k) RP_50 + IR_50\%

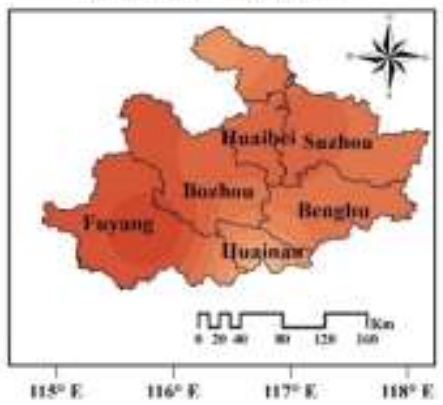

(c) RP $5+$ IR $100 \%$

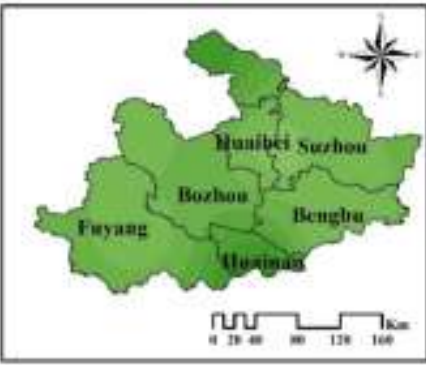

(f) RP_10 + IR_ $100 \%$

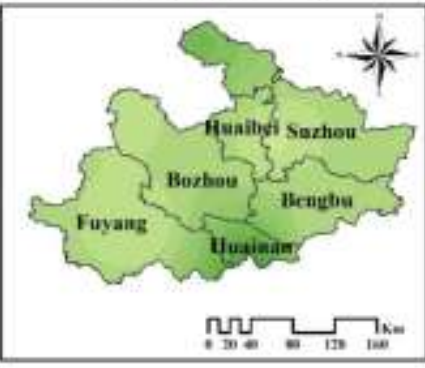

(i) RP_20 + IR_100\%

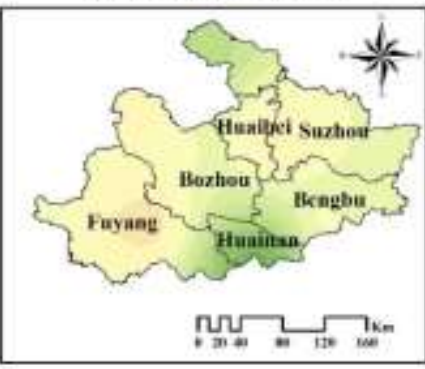

(I) RP_50+IR_100\%

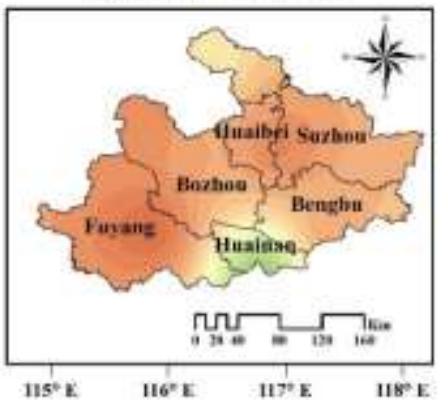

Legend

$(\%)$

Figure 9. Spatial distribution of drought loss risk under different drought return periods in Huaibei Plain of Anhui Province.

\section{Conclusion}

The regional drought loss risk can be described as the possible loss of disaster-bearing bodies when suffered a specific drought event in the hazard-formation environment. This study combined the drought risk system theory and crop growth simulation, quantitatively evaluate the intensity of historical drought and assess the drought loss risk in Huaibei Plain of Anhui Province.

The spatio-temporal distribution of historical drought events characteristics in study area was 
described by occurring frequency. The statistical results showed that the northern regions including Huaibei and Suzhou were low-intensity high-frequency areas, while the southern regions like Huainan and Bengbu were high-intensity low-frequency areas. Moreover, some extreme drought events were also consistent with the actual records, which also validated the accuracy and reliability of the identification results.

The drought loss risk curves can reflect the dynamic process that drought events attracted negative responses of soybean yield with the influence of irrigation, and the loss risk caused by drought can be quantified by the yield loss rate. When suffered a similar drought event, the drought risk was decreased with the increasing irrigation level. While with the same irrigation scheme, the drought loss risk of soybean was decreased with the increasing occurring frequency of drought events. Moreover, the assumed irrigation schemes in this study had a better effect on mitigating the loss risk in mild drought events than in severe drought events.

The drought loss risk distribution maps of study area were plotted based on the risk curves. The risk map included information about drought intensity (reappearance periods) drought resistance capability (irrigation levels), and the possible yield loss, which was an intuitive expression of the spatio-temporal distribution characteristics of drought loss risk. The results showed that the potential drought loss risk (without irrigation) in the western region (Fuyang) was highest, while in the southern area (Bengbu) was lower. The assumed irrigation schemes can effectively reduce the drought loss risk, however, the efficiencies of irrigation were affected by the spatio-temporal distribution of precipitation. The drought risk reduction effect of irrigation in Huainan was better than that of other sub-regions, especially better than Fuyang. For local agricultural drought risk management purposes, the above drought risk distribution maps were useful for identifying the weak regions and projects. For example, the Fuyang was suggested to strengthen the agricultural drought monitoring in the critical stages of crops, while the Huainan could further optimizing the irrigation schemes.

The drought risk curves and risk maps in Huaibei Plain of Anhui Province were the main results of this application, which was useful for understanding the distribution characteristics of historical drought events and comparing the agricultural drought loss risk in various regions. This study constructed and practiced a quantitative framework for regional drought risk assessment. However, the results were obtained based on the historical data and crop growth simulation, which were lacking in considering the influence of climate change in the future. Therefore, predicting the dynamic drought risk in the future and make assessments, is an important further work of this study.

\section{Declaration of competing interest}

The authors declare that they have no known competing financial interests or personal relationships that could have appeared to influence the work reported in this paper.

Acknowledgments The authors would like to thank the support of the National Key Research and Development Program of China under Grant No. 2017YFC1502405, the National Natural Science Foundation of China under Grand No. 52109009, the Natural Science Foundation of Anhui Province under Grant No. 2108085QE254, the Fundamental Research Funds for the Central Universities under Grant Nos. JZ2021HGTA0165, JZ2020HGQA0202, JZ2021HGQB0281, and the China Scholarship Council. 


\section{References}

Ali, S.A., Khatun, R., Ahmad, A., Ahmad, S.N., 2020. Assessment of Cyclone Vulnerability, Hazard Evaluation and Mitigation Capacity for Analyzing Cyclone Risk using GIS Technique: a Study on Sundarban Biosphere Reserve, India. Earth Systems and Environment. 4(1), 71-92. https://doi.org/10.1007/s41748-019-00140-x.

Angstrom, A., 1924. Solar and terrestrial radiation. Report to the international commission for solar research on actinometric investigations of solar and atmospheric radiation. Quarterly Journal of the Royal Meteorological Society. 50, 135-138. https://doi.org/10.1002/qj.49705021008.

Bahrami, M., Bazrkar, S., Zarei, A.R., 2018. Modeling, prediction and trend assessment of drought in Iran using standardized precipitation index. Journal of Water and Climate Change. 10(1), 181-196. https://doi.org/10.2166/wcc.2018.174.

Benjamin, J.G., Nielsen, D.C., 2006. Water deficit effects on root distribution of soybean, field pea and chickpea. Field Crops Research. 97, 248-253. https://doi.org/10.1016/j.fcr.2005.10.005.

Carrao, H., Naumann, G., Barbosa, P., 2016. Mapping global patterns of drought risk: An empirical framework based on sub-national estimates of hazard, exposure and vulnerability. Global Environmental Change. 39, $108-124$. https://doi.org/10.1016/j.gloenvcha.2016.04.012.

Crocetti, L., Forkel, M., Fischer, M., Jurečka, F., Grlj, A., Salentinig, A., Trnka, M., Anderson, M., Ng, W.-T., Kokalj, Ž., Bucur, A., Dorigo, W., 2020. Earth Observation for agricultural drought monitoring in the Pannonian Basin (southeastern Europe): current state and future directions. Regional Environmental Change. 20(4), 123. https://doi.org/10.1007/s10113-020-01710-w.

Cui, Y., Jiang, S., Jin, J., Ning, S., Feng, P., 2019. Quantitative assessment of soybean drought loss sensitivity at different growth stages based on S-shaped damage curve. Agricultural Water Management. 213, 821-832. https://doi.org/10.1016/j.agwat.2018.11.020.

Dabanli, I., 2018. Drought hazard, vulnerability, and risk assessment in Turkey. Arabian Journal of Geoences. 11(18), 538. https://doi.org/10.1007/s12517-018-3867-x.

Elkollaly, M., Khadr, M., Zeidan, B., 2018. Drought analysis in the Eastern Nile basin using the standardized precipitation index. Environmental Science and Pollution Research. 25, 30772-30786. https://doi.org/10.1007/s11356-016-8347-9.

Fei, Z., 2014. Study on the Risk Assessment of Regional Agricultural Drought. Hefei University of Technology, Hefei city, China.

Fontaine, M.M., Steinemann, A.C., M.ASCE, 2009. Assessing Vulnerability To Natural Hazards: Impact-based Method And Application To Drought In Washington State. Natural Hazards Review. 10(1), 11-18. https://doi.org/10.1061/(ASCE)1527-6988(2009)10:1(11).

Ghulam, A., Li, Z., Qin, Q., Tong, Q., 2007. Exploration of the spectral space based on vegetation index and albedo for surface drought estimation. Journal of Applied Remote Sensing. 1, 341-353. https://doi.org/10.1117/1.2784792.

Halwatura, D., Lechner, A.M., Arnold, S., 2015. Drought severity-duration-frequency curves: a foundation for risk assessment and planning tool for ecosystem establishment in post-mining landscapes. Hydrology and Earth System Sciences. 19, 1069-1091. https://doi.org/10.5194/hess-19-1069-2015.

Hao, L., Zhang, X., Liu, S., 2012. Risk assessment to China's agricultural drought disaster in county unit. Natural Hazards. 61(2), 785-801. https://doi.org/10.1007/s11069-011-0066-4.

Hao, Z., Aghakouchak, A., 2014. A Nonparametric Multivariate Multi-Index Drought Monitoring Framework. Journal of Hydrometeorology. 15(1), 89-101.

Henry, A.J., 1907. Climatology of the United States. Nature. 76, 11-12. https://doi.org/10.1038/076011a0.

Hsiao, T.C., Acevedo, E., 1974. Plant responses to water deficits, water-use efficiency, and drought resistance. 
Agricultural Meteorology. 14(1-2), 59-84. https://doi.org/10.1016/0002-1571(74)90011-9.

Hsiao, T.C., Heng, L., Steduto, P., Rojas-Lara, B., Raes, D., Fereres, E., 2009. AquaCrop-The FAO Crop Model to Simulate Yield Response to Water: III. Parameterization and Testing for Maize. Agronomy Journal. 101(3), 448459. https://doi.org/10.2134/agronj2008.0218s.

$\mathrm{Hu}$, Y., You, F., 2015. Review of the Evolution Mechanism of Grain Crop Planting Structure in China. Chinese Agricultural Science Bulletin. 15(2), 87-93.

Jin, J., Son, Z., Cui, Y., Zhou, Y., Jiang, S., He, J., 2016. Research progress on the key technologies of drought risk assessment and control. Journal of Hydraulic Engineering. 47(3), 398-412. https://doi.org/10.13243/j.cnki.slxb.20150945.

Jones, J.W., Hoogenboom, G., Porter, C.H., Boote, K.J., Batchelor, W.D., Hunt, L.A., Wilkens, P.W., Singh, U., Gijsman, A.J., Ritchie, J.T., 2003. The DSSAT cropping system model. European Journal of Agronomy. 18, 235265. https://doi.org/10.1016/S1161-0301(02)00107-7.

Keith, B., Andrew, B., 2014. GLUE: 20 years on. Hydrological Processes. 28, 5897-5918. https://doi.org/10.1002/hyp.10082.

Lee, T., Modarres, R., Ouarda, T.B.M.J., 2013. Data-based analysis of bivariate copula tail dependence for drought duration and severity. Hydrological Processes. 27(10), 1454-1463. https://doi.org/10.1002/hyp.9233.

Lesk, C., Rowhani, P., Ramankutty, N., 2016. Influence of extreme weather disasters on global crop production. Nature. 529(7584), 84-87. https://doi.org/10.1038/nature16467.

Li, J., Wu, C., Xia, C.-A., Yeh, P.J.-F., Hu, B.X., Huang, G., 2021. Assessing the responses of hydrological drought to meteorological drought in the Huai River Basin, China. Theoretical and Applied Climatology. 144, 10431057. https://doi.org/10.1007/s00704-021-03567-3.

Liu, H., Jiang, S., Jin, J., Li, J., Zhou, Y., Liu, L., 2013. A GIS-based Approach to Regional Drought Risk Zoning. Journal of Catastrophology. 28, 198-203.

Liu, Y., Chen, J., 2020. Future global socioeconomic risk to droughts based on estimates of hazard, exposure, and vulnerability in a changing climate. Science of The Total Environment. 751(2), 142-159. https://doi.org/10.1016/j.scitotenv.2020.142159.

Malik, W., Dechmi, F., 2019. DSSAT modelling for best irrigation management practices assessment under Mediterranean conditions. Agricultural Water Management. 216, 27-43. https://doi.org/10.1016/j.agwat.2019.01.017.

Masoliver, J., 2009. Extremes in Nature: An Approach Using Copulas. Journal of Statistical Physics. $134,425$. https://doi.org/10.1007/s10955-008-9666-0.

McKee, T.B., Doesken, N.J., Kleist, J., 1993. The Relationship of Drought Frequency and Duration to Time Scales. Eighth Conference on Applied Climatology.

Mehdikhani, H., Saghafian, B., Arasteh, P.D., 2016. A new damage-probability approach for risk analysis of rain-fed agricultural systems under meteorological drought. KSCE Journal of Civil Engineering. 21, 1453-1461. https://doi.org/10.1007/s12205-016-0510-y.

Mishra, A.K., Singh, V.P., 2011. Drought modeling - A review. Journal of Hydrology. 403(1-2), 157-175. https://doi.org/10.1016/j.jhydrol.2011.03.049.

Palmer, W.C., 1968. Keeping Track of Crop Moisture Conditions, Nationwide: The New Crop Moisture Index. Weatherwise. 21(4), 156-161. https://doi.org/10.1080/00431672.1968.9932814.

Pinkayan, S., 1966. Conditional probabilities of occurrence of wet and dry years over a large continental area. Colorado State University, Colorado, America.

Prabnakorn, S., Maskey, S., Suryadi, F.X., Fraiture, C.d., 2019. Assessment of drought hazard, exposure, vulnerability, and risk for rice cultivation in the Mun River Basin in Thailand. Natural Hazards. 97, 891-911. 
https://doi.org/10.1007/s11069-019-03681-6.

Qu, Y., 2018. Study on Drought Disaster Risk Assessment Theory and Method-A Case Study of Agricultural drought in Liaoning Province. China Institute of Water Resources \& Hydropower Research, Beijing, China.

Riboli, E., Kaaks, R., 1997. The EPIC Project: rationale and study design. European Prospective Investigation into Cancer and Nutrition. International Journal of Epidemiology. 26(1), 6-14. https://doi.org/10.1093/ije/26.suppl_1.S6.

Saddique, Q., Cai, H., Xu, J., Ajaz, A., He, J., Yu, Q., Wang, Y., Chen, H., Khan, M.I., Liu, D.L., He, L., 2020. Analyzing adaptation strategies for maize production under future climate change in Guanzhong Plain, China. Mitigation and Adaptation Strategies for Global Change. 25, 1523-1543. https://doi.org/10.1007/s11027-02009935-0.

Salmeron, M., Purcell, L.C., Vories, E.D., Shannon, G., 2017. Simulation of genotype-by-environment interactions on irrigated soybean yields in the U.S. Midsouth. Agricultural Systems. 150, 120-129. https://doi.org/10.1016/j.agsy.2016.10.008.

Santos, J.F., Portela, M.M., Pulido-Calvo, I., 2011. Regional Frequency Analysis of Droughts in Portugal. Water Resources Management. 25(14), 3537-3558. https://doi.org/10.1007/s11269-011-9869-z.

Shahid, S., Behrawan, H., 2008. Drought risk assessment in the western part of Bangladesh. Natural Hazards. 46(3), 391-413. https://doi.org/10.1007/s11069-007-9191-5.

Shi, P., Xu, W., Ye, T., He, C., Wang, J., Li, N., 2011. Developing Disaster Risk Science:Discussion on the Disaster Reduction Implementation Science. Journal of Natural Disaster Science. 32, 79-88. https://doi.org/10.2328/jnds.32.79.

Shiau, J.-T., Shen, H.W., 2001. Recurrence Analysis of Hydrologic Droughts of Differing Severity. Journal of Water Resources Planning \& Management. 127, 30-40. https://doi.org/10.1061/(ASCE)0733-9496(2001)127:1(30).

Siad, S.M., Iacobellis, V., Zdruli, P., Gioia, A., Stavi, I., Hoogenboom, G., 2019. A review of coupled hydrologic and crop growth models. Agricultural Water Management. 224, 105746. https://doi.org/10.1016/j.agwat.2019.105746.

Spinoni, J., Naumann, G., Carrao, H., Barbosa, P., Vogt, J., 2014. World drought frequency, duration, and severity for 1951-2010. International Journal of Climatology. 34(8), 2792-2804. https://doi.org/10.1002/joc.3875.

Sun, K., Chen, J., Xu, J., Wu, J., 2013. Study on the assessment method of spring drought risk for rice in Yuanmou county, Yunnan province based on the EPIC model. Journal of Hydraulic Engineering. 44(11), 1326-1332. https://doi.org/10.13243/j.cnki.slxb.2013.11.009.

Sun, Z., Zhang, J., Yan, D., Wang, C., Liu, X., Tong, Z., 2012. Risk spatial evolution of drought disaster study in Anhui Province based on GIS. Journal of Northeast Normal University(Natural Science Edition). 44, $133-137$.

Taiz, L., Zeiger, E., 2015. Plant Physiology and Development. Sinauer Associates, Oxford, America.

Wang, J., Guo, J., Qing, J., 2007. Application of a Kind of K Drought Index in the Spring Drought Analysis in Northwest China. Journal of Natural Resources. 22(5), 709-717.

Wang, R., Zhang, J., Guo, E., Alu, S., Li, D., Ha, S., Dong, Z., 2019a. Integrated drought risk assessment of multihazard-affected bodies based on copulas in the Taoerhe Basin, China. Theoretical and Applied Climatology. 135, 577-592. https://doi.org/10.1007/s00704-018-2374-z.

Wang, R., Zhao, C., Zhang, J., Guo, E., Li, D., Alu, S., Ha, S., Dong, Z., 2019b. Bivariate copula function-based spatial-temporal characteristics analysis of drought in Anhui Province, China. Meteorology and Atmospheric Physics. 131, 1341-1355. https://doi.org/10.1007/s00703-018-0640-3.

Wei, Y., Jin, J., Cui, Y., Ning, S., Fei, Z., Wu, C., Zhou, Y., Zhang, L., Liu, L., Tong, F., 2021. Quantitative assessment of soybean drought risk in Bengbu city based on disaster loss risk curve and DSSAT. International Journal of Disaster Risk Reduction. 56, 102126. https://doi.org/10.1016/j.ijdrr.2021.102126. 
Wu, H., Hayes, M.J., Wilhite, D.A., Svoboda, M.D., 2005. The effect of the length of record on the standardized precipitation index calculation. International Journal of Climatology. 25(4), 505-520. https://doi.org/10.1002/joc.1142.

Yan, L., 2020. Simulation of wheat growth and development process based on the CERES-Wheat model. Northwest A \& F University, Yangling city, China.

Yao, N., 2020. Spatio-temporal evolution of drought and future projections under climate change. Northwest A \& F University, Yangling city, China.

Yao, N., Li, Y., Xu, F., Liu, J., Chen, S., Ma, H., Chau, H.W., Liu, D.L., Li, M., Feng, H., Yu, Q., He, J., 2020. Permanent wilting point plays an important role in simulating winter wheat growth under water decit conditions. Agricultural Water Management. 229, 105954. https://doi.org/10.1016/j.agwat.2019.105954.

Yevjevich, V., 1969. An objective approach to definitions and investigations of continental hydrologic droughts. Journal of Hydrology. 7(3), 353.

Yin, J., Ye, M., Yin, Z., Xu, S., 2015. A review of advances in urban flood risk analysis over China. Stochastic Environmental Research \& Risk Assessment. 29(3), 1063-1070. https://doi.org/10.1007/s00477-014-0939-7.

Yuhas, A.N., Scuderi, L.A., 2009. MODIS-derived NDVI Characterisation of Drought-Induced Evergreen Dieoff in Western North America. Geographical Research. 47(1), 34-45. https://doi.org/10.1111/j.17455871.2008.00557.x.

Zhai, W., 2007. China Meteorological Disasters Dictionary (Anhui). China Meteorological Press, Beijing, China.

Zhang, F., Chen, Y., Zhang, J., Guo, E., Wang, R., Li, D., 2019. Dynamic drought risk assessment for maize based on crop simulation model and multi-source drought indices. Journal of Cleaner Production. 233(28), 100-114. https://doi.org/10.1016/j.jclepro.2019.06.051.

Zhang, J., Sheng, S., Wang, X., 2014. Temporal and Spatial Distribution Characteristics of Drought During Summer Corn Growing Season in Anhui Province. Journal of Arid Meteorology. 32, 163-168.

Zhang, T., Xu, W., Lin, X., Yan, H., Ma, M., Zhenyan He, 2019. Assessment of heavy metals pollution of soybean grains in North Anhui of China. Science of The Total Environment. 646, 914-922. https://doi.org/10.1016/j.scitotenv.2018.07.335.

Zhao, J., Zhang, Q., Zhu, X., Shen, Z., Yu, H., 2020. Drought risk assessment in China: Evaluation framework and influencing factors. Geography and Sustainability. 1(3), 220-228. https://doi.org/10.1016/j.geosus.2020.06.005.

Zhou, Y., Zhou, P., Jin, J., Lli, J., 2014. Establishment of hydrological drought index based on sources of regional water supply and its application to drought frequency analysis for Kunming. Journal of Hydraulic Engineering. 45(9), 1038-1047. https://doi.org/10.13243/j.cnki.slxb.2014.09.004.

Ziaei, A.N., Sepaskhah, A.R., 2003. Model for simulation of winter wheat yield under dryland and irrigated conditions. Agricultural Water Management. 58(1), 1-17. https://doi.org/10.1016/S0378-3774(02)00080-X. 